\title{
Health Beliefs of Nursing Faculty Students about Breast Cancer and Self Breast Examination
}

\author{
Melek Ardahan ${ }^{1 *}$, Hulya Dinc ${ }^{2}$, Askin Yaman $^{3}$, Emrah Aykir ${ }^{4}, B_{\text {Baver Aslan }}^{5}$
}

\begin{abstract}
Background: Breast cancer usually shows a slow development rate and when it is recognized in early stages very successful treatment results can be achieved. This research was planned to research the health beliefs of nursing faculty students about breast cancer and breast self-examination (BSE). Materials and Methods: The first class students of nursing faculty formed the basis for this descriptive research $(\mathrm{N}=347)$. Sample selection was not made and all female students who wanted to participate voluntarily in the research during March-May of 2014 were included ( $n=331)$. Results: It was determined that $85.5 \%$ of students had knowledge about cancer, $79.5 \% \mathrm{knew}$ of breast cancer, and $65.3 \%$ were aware of how BSE is performed. According to the responses of students to the scale of the health belief model that is used to determine the health beliefs of students, item-point averages of trust and obstacle sub-dimensions were high. Conclusions: It is determined that more than half of students had knowledge about breast cancer and breast self-examination. Their health beliefs were affected by trust and obstacle perceptions, knowledge level about cancer, and awareness about how BSE is done. These factors should be considered in planning trainings that will be given to students. Social responsibility projects should have designed to create the awareness that cancer is a treatable disease.
\end{abstract}

Keywords: Breast cancer - breast self-examination - health beliefs - Turkish nursing faculty students

Asian Pac J Cancer Prev, 16 (17), 7731-7736

\section{Introduction}

Cancer is a disease that is characterized by uncontrolled cellular growth, local tissue, and regional lymph nodes invasion as well as distant metastases (Barnett et al., 2014). Breast cancer (BC) is a malignant tumor that starts from cells of the breast. BC occurs mainly in women (WHO, 2013) one out of every 10 cases is BC (Varughese et al., 2015). The age standardized incidence rate of the disease is as follows: North America, 126 (Toriola et al., 2013), Turkey 35.8 (Kayhan et al., 2014) and Russia 43.2 (Troisi et al., 2012) per 100, 000 people. Breast cancer is the most commonly diagnosed type of cancer and the second leading cause of cancer related death among women (Yilmaz and Arslan, 2015). Various studies recognized factors like genetic (Afsharfard et al., 2013), duration of breastfeeding, birth rate, number of cigarettes smoked and the duration of it (Fredslund et al., 2012), family history of cancer, the number of abortions (Bjerkaas et al., 2013) and some other factors affected the disease.

Early detection of breast cancer is crucial for early treatment and reduction in related mortality. Recommended screening methods to reduce breast cancer mortality and morbidity include breast self-examination (BSE), clinical breast examination (CBE), and mammography (Ersin and Bahar 2013; Yilmaz et al., 2013). Although, there is debate surrounding the efficacy of routine BSE in early detection of breast cancer (Giridhara et al., 2011). But, among women older than 20 years, BSE recommended as a screening method for increasing breast health awareness, because it is cheap, widely available, and does not require complex technical training (Giridhara et al., 2011).

Studies indicate that women's health beliefs and attitudes are the most important factors which influence whether or not they will get screened for breast cancer (Erbil and Bolukbas, 2014; Jirojwong and McLennan, 2003). The Health Belief Model has been used in studies as a theoretical framework to study BSE and other breast cancer detection behaviors. According to this model, women who present a higher risk for breast cancer, perceive breast cancer as a serious threat to their own health, have a low perception barrier, and who possess a high perception of the benefits will be more likely to practice BSE on a regular basis (Hajian-Tilaki and Auladi, 2012).

The nurses have an important role in terms of learning and practicing the BSE by women in the society. In various studies, it is determined that the women informed by 
the nurses regarding the early diagnosis of cancer have higher percentage of regular BSE than the non-informed women (Jane, 1995). The health training program which would plan for women by nurses has included behaviors regarding health improvement such as BSE. The nurses should have sufficient knowledge and capability regarding the subject while they were preparing and also applying the training programs for society. This knowledge can be gained in schools or courses. In this regard the ideal one is that the students of nursing would have graduated with sufficient knowledge and capability regarding breast cancer. In the results of studies regarding BSE on the students of nursing, it is determined that the breast examination made regularly each month was not at the desired level (Aydin et al., 2003). Aydin and Isikli, (2004), 26.5\% of nursing students were made examination regularly each month, even Yasaroglu (1995) was detected that $70 \%$ of the students studying medical education made BSE minimum once, even these students didn't made examination regularly each month. Erbil and Bolukbas (2014) reported that knowledge about breast cancer and young women's practices and beliefs about BSE are not enough to increase their survival rates. Examining the knowledge and applications of nursing students regarding BSE would help to determine their behavior related to health improvement and also it would be an indicator how much they can help other women in their Professional life. From this point of view, it was aimed to determine the health beliefs of the first class students of nursing faculty.

\section{Materials and Methods}

\section{Sample}

The first class students of the nursing faculty was formed the universe of descriptive research $(\mathrm{N}=347)$. Sample selection was not made in the study, the female students who wanted to participate voluntarily to the research during March-May 2014 period were included in the research $(n=331)$.

\section{Data collection}

To gather the data for research, a questionnaire form with total 13 question formed 6 question regarding descriptive characteristics of student and 7 question regarding breast cancer and breast self-examination and the scale of health belief model (SHBM) (42 items) were used. For each item, participants were asked to rate their level of agreement using a five-point Likert scale from one (strongly disagree) to five (strongly agree).

\section{Validity and reliability analysis}

Validity and Reliability Analysis of the scale of Health Belief Model was made and the results are located in the following tables (Table 1, Table 2).

The psychometric assesments made for evaluating the reliability of SHBM are indicated that the scale is demandable. In the study of Gozum and Aydin, four item have been attached the factors which are different from their dimensions. Three of these items (motivation 6 , 7 and barriers 1) were removed because of having low correlation with total point of their own dimensions, and also the other one (seriousness 5) was remained because of having good correlation with its own dimension (Munro and Page, 1993). In the Karayurt study, the factor structure was found compatible with English Form except gathering the dimensions of Self Breast Examination Barriers under two separate factors. The two factor was combined because of the correlation of two factors within the barriers dimension were high $(\mathrm{r}=0.65, \mathrm{p}<.01)$ (Karayurt, 2003). The confirmatory factor was used to evaluate the validity of structure of SHBM in both studies. A proof for validity for Turkish form was provided whereas the factors obtained from both studies were similar to English form (Gozum and Aksayan, 2003).

\section{Ethical approval}

The study was made by getting verbal permission from the students participated to the research, and by obtaining written permission from Ege University Nursing Faculty.

\section{Data analysis}

The data were evaluated by SPSS 21.0 (Statistical Package of Social Science) statistic program. The descriptive statistics, number and percentage distributions were made within data analysis. Also the regression analysis was made in determining the relationships with independent variable.

\section{Results}

The descriptive characteristics of students

It is determined that $74 \%$ of students were between 19-20 years of age. $20.2 \%$ of them were $21-22$ years of age, $3.3 \%$ of them were $23-24$ years of age and $\% 2.5$ of were 25 and over years of age. When the recent schools that they graduated were evaluated, the Anatolian High Schools have taken the first place. The general high schools have followed it with $29.9 \%$; the vocational schools have followed with $2.7 \%$ (including the health vocational schools) and science high school with $1.9 \%$ and the other high schools with $1.8 \%$. The questions regarding the educational status of their parents were asked to the students. When the educational status of their mothers were reviewed, it has been detected that $7.3 \%$ of them were illiterate, $14.8 \%$ of them were literate, $50.5 \%$ of them were graduated from elementary school, $23.3 \%$ of them

\section{Table 1. Item Statistics Results of SHBM}

\begin{tabular}{|c|c|c|}
\hline \multirow[t]{2}{*}{ Sub-Dimensions } & \multicolumn{2}{|c|}{ Item-Total Point Correlation } \\
\hline & Gozum-Aydin Karayurt & Ardahan \\
\hline Susceptibility & $0.44-0.550 .35-0.49$ & $0.30-0.50$ \\
\hline Seriousness & $0.31-0.610 .35-0.62$ & $0.40-0.58$ \\
\hline Health Motivation & $0.40-0.540 .41-0.66$ & $0.35-0.60$ \\
\hline Benefits of BSE & $0.42-0.770 .56-0.74$ & $0.51-0.70$ \\
\hline Barriers of BSE & $0.34-0.470 .30-0.53$ & $0.38-0.49$ \\
\hline Confidence & $0.35-0.590 .30-0.70$ & $0.45-0.70$ \\
\hline Benefits of Mammography & $0.36-0.68$ & - \\
\hline Barriers of Mammography & $0.33-0.64$ & - \\
\hline
\end{tabular}

*The items with item- total point correlation coefficient below 30 were removed from the form 
were graduated from high school and $4.1 \%$ of them were graduated from university. When the educational status of their fathers were reviewed, it has been detected that $42.9 \%$ of them were graduated from elementary school, $30.8 \%$ of them were graduated from high school, $13.6 \%$ of them were graduated from university, $8.8 \%$ of them were literate and 3.95 Of them were illiterate.

The knowledge of students about breast cancer and selfbreast examination

It is determined that $85.5 \%$ of students have knowledge about cancer, $14.5 \%$ of them have no knowledge about cancer. When someone mentioned cancer it was detected that $42.3 \%$ of students thought of chemotherapy, 32.3 of them thought of disease and 25.4 of them thought of death. It was detected that 79.5 of students were known about what is the breast cancer and the $12 \%$ of them were unstable. 65.3 Of students were known how the SBE is made, $19 \%$ of them weren't known and 15.7 of them were unstable.

It is detected that $37 \%$ of students knew what is the breast cancer were learned $37 \%$ from family/friend/ teachers, $24 \%$ from communication tools and media, 17.1 from internet and health professionals, $7.9 \%$ from scientific sources. The ones knew what is the SBE were learned from $35.2 \%$ from family/friend/teachers, $20.4 \%$ from communication tools and media, 21.2 from healthcare professionals, $14.4 \%$ from internet and 8.3 from articles and books.

It was detected that $76.4 \%$ of students have no family member experiencing/experienced breast cancer, $16.3 \%$ of them have at least one member and $7.3 \%$ of them do not know it. It has been detected that $41.1 \%$ of students participated to the research were known the diagnosis methods of breast cancer, $32.3 \%$ of them were not known and $26.6 \%$ of them were unstable.

\section{The averages of sub-dimension item points of health belief} model scale

The minimum and maximum points of sub-dimensions of scale and item point averages were determined according to the responses of students to the Scale of Health Belief Model used for determining the health belief of the students. The averages of sub dimensions and Standard deviations; susceptibility was 7.42 \pm 2.34 (min:3, max:15), seriousness was 21.66 \pm 5.26 ( $\min : 7$, max: $35)$, benefit was $16.10 \pm 3.48$ (min:4, $\max : 20)$, barriers was 27.31 \pm 8.44 (min:11, max:55), confidence was 32.90 \pm 7.77 (min: 10, max: 50), health motivation was 26.84 \pm 5.09 (min:8, max: 35).

The relationship of the averages of sub-dimension item point of health belief model scale with independent variables

According to the responses of the students; it is determined that the average of susceptibility subdimension item point of Health Belief Model was not affected by independent variables $(\mathrm{F}=1.908 \mathrm{p}=0.079)$. It was detected that the average point of seriousness subdimension were increased linearly by the first thing (such as disease, death) came to the mind regarding cancer. The correlation between the average point of seriousness sub-dimension and independent variables was (R) 0.21. When the linearity of this correlation was evaluated, it was detected that the correlation is statistically significant and linear $(\mathrm{F}=2.451 \mathrm{p}<0.05)$. It was detected that the knowledge of students about cancer increased the average of benefit sub-dimension point. The correlation between the average of benefit sub-dimension point and independent variables was (R) 0.38.

When the linearity of this correlation was evaluated, it was detected that the correlation is statistically significant and linear $(\mathrm{F}=9.148 \mathrm{p}<0.01)$. It was detected that the average points of students took from the barriers subdimension of scale were increased linearly by existence of a member with breast cancer in the family and the first thing (such as disease, death) came into mind regarding cancer. The correlation between the average points of obstacle sub-dimension was (R) 0.33 . When the linearity of this correlation was evaluated, it was detected that the correlation is statistically significant and linear $(\mathrm{F}=6.765$ $\mathrm{p}<0.01)$. It was detected that the knowledge of students regarding cancer and BSE increased the average of confidence sub-dimension point. The correlation between the average of trust sub dimension point and independent variables is $(\mathrm{R}) 0.39$. When the linearity of this correlation was evaluated, it was detected that the correlation is statistically significant and linear $(F=9.598 \mathrm{p}<0.01)$. It was detected that the existence of a member with breast cancer in the family increased the average of health motivation sub-dimension linearly. The correlation between the average of health motivation sub dimension point and independent variables is (R) 0.21 . When the linearity of this correlation was evaluated, it was detected that the correlation is statistically significant and linear $(\mathrm{F}=2.546$ $\mathrm{p}<0.05$ ) (Table 3).

Table 2. Cronbach Alpha Coefficients of SHBM

\begin{tabular}{lccc}
\hline Dimensions & $\begin{array}{c}\text { Turkish Form }(\mathrm{N}=266) \\
\text { Gozum-Aydin Cronbach }\end{array}$ & $\begin{array}{c}\text { Turkishform }(\mathrm{N}=430) \\
\text { KarayurtCronbach }\end{array}$ & $\begin{array}{c}\text { Turkish form }(\mathrm{N}=331) \\
\text { ArdahanCronbach }\end{array}$ \\
\hline Susceptibility & 0.69 & 0.58 & 0.63 \\
Seriousness & 0.75 & 0.80 & 0.85 \\
Health Motivation & 0.83 & 0.78 & 0.70 \\
Benefits of BSE & 0.83 & 0.85 & 0.83 \\
Barriers of BSE & 0.73 & 0.68 & 0.75 \\
Confidence & 0.82 & 0.89 & 0.80 \\
Benefits of Mammography & 0.80 & - & - \\
Barriers of Mammography & 0.81 & - & - \\
\hline
\end{tabular}


Table 3. The Regression Analysis of the Average of Sub Dimension Item Point of Scale of Health Belief Model with Independent Variables

\begin{tabular}{|c|c|c|c|}
\hline Sub-dimensions & Beta & $\mathrm{t}$ & $\mathrm{p}$ \\
\hline \multicolumn{4}{|l|}{ Susceptibility } \\
\hline The knowledge about cancer & 0.104 & 1.771 & 0.077 \\
\hline The first thing came into mind regarding cancer (disease, Death etc.) & 0.098 & 1.785 & 0.075 \\
\hline Knowledge about what is the breast cancer & 0.002 & 0.036 & 0.971 \\
\hline Knowledge about how the SBE can be made & 0.002 & 0.032 & 0.974 \\
\hline Family members with breast cancer & 0.099 & 1.754 & 0.080 \\
\hline Knowledge about diagnosis methods of breast cancer & 0.020 & 0.331 & 0.741 \\
\hline \multicolumn{4}{|c|}{$\mathrm{R}=0.185, \mathrm{R} 2=0.034, \mathrm{~F}=1.908, \mathrm{p}=0.079$} \\
\hline \multicolumn{4}{|l|}{ Seriousness } \\
\hline The knowledge about cancer & 0.081 & 1.386 & 0.167 \\
\hline The first thing came into mind regarding cancer (disease, Death etc.) & 0.188 & 3.428 & 0.001 \\
\hline Knowledge about what is the breast cancer & 0.039 & 0.643 & 0.521 \\
\hline Knowledge about how the SBE can be made & 0.025 & 0.427 & 0.669 \\
\hline Family members with breast cancer & 0.048 & 0.859 & 0.391 \\
\hline Knowledge about diagnosis methods of breast cancer & 0.003 & 0.044 & 0.965 \\
\hline \multicolumn{4}{|l|}{$\mathrm{R}=0.208, \mathrm{R} 2=0.043, \mathrm{~F}=2.451, \mathrm{p}=0.025$} \\
\hline \multicolumn{4}{|l|}{ Benefits } \\
\hline The knowledge about cancer & 0.304 & 5.504 & 0.000 \\
\hline The first thing came into mind regarding cancer (disease, Death etc.) & 0.071 & 1.363 & 0.174 \\
\hline Knowledge about what is the breast cancer & 0.051 & 0.883 & 0.378 \\
\hline Knowledge about how the SBE can be made & 0.101 & 1.806 & 0.072 \\
\hline Family members with breast cancer & 0.104 & 1.947 & 0.052 \\
\hline Knowledge about diagnosis methods of breast cancer & 0.080 & 1.411 & 0.159 \\
\hline \multicolumn{4}{|c|}{$\mathrm{R}=0.381, \mathrm{R} 2=0.145, \mathrm{~F}=9.148, \mathrm{p}=0.000$} \\
\hline \multicolumn{4}{|l|}{ Barriers } \\
\hline The knowledge about cancer & 0.107 & 1.896 & 0.059 \\
\hline The first thing came into mind regarding cancer (disease, Death etc.) & 0.182 & 3.449 & 0.001 \\
\hline Knowledge about what is the breast cancer & 0.034 & 0.578 & 0.564 \\
\hline Knowledge about how the SBE can be made & 0.064 & 1.119 & 0.264 \\
\hline Family members with breast cancer & 0.220 & 4.054 & 0.000 \\
\hline Knowledge about diagnosis methods of breast cancer & 0.108 & 1.871 & 0.062 \\
\hline \multicolumn{4}{|c|}{$\mathrm{R}=0.334, \mathrm{R} 2=0.111, \mathrm{~F}=6.765, \mathrm{p}=0.000$} \\
\hline \multicolumn{4}{|l|}{ Confidence } \\
\hline The knowledge about cancer & 0.117 & 2.131 & 0.034 \\
\hline The first thing came into mind regarding cancer (disease, Death etc.) & 0.013 & 0.246 & 0.806 \\
\hline Knowledge about what is the breast cancer & 0.016 & 0.282 & 0.778 \\
\hline Knowledge about how the SBE can be made & 0.308 & 5.513 & 0.000 \\
\hline Family members with breast cancer & 0.044 & 0.832 & 0.406 \\
\hline Knowledge about diagnosis methods of breast cancer & 0.067 & 1.186 & 0.237 \\
\hline \multicolumn{4}{|c|}{$\mathrm{R}=0.388, \mathrm{R} 2=0.151, \mathrm{~F}=9.598, \mathrm{p}=0.000$} \\
\hline \multicolumn{4}{|l|}{ Health Motivation } \\
\hline The knowledge about cancer & 0.074 & 1.275 & 0.203 \\
\hline The first thing came into mind regarding cancer (disease, Death etc.) & 0.028 & 0.506 & 0.613 \\
\hline Knowledge about what is the breast cancer & 0.038 & 0.621 & 0.535 \\
\hline Knowledge about how the SBE can be made & 0.093 & 1.563 & 0.119 \\
\hline Family members with breast cancer & 0.136 & 2.421 & 0.016 \\
\hline Knowledge about diagnosis methods of breast cancer & 0.046 & 0.771 & 0.441 \\
\hline \multicolumn{4}{|c|}{$\mathrm{R}=0.212, \mathrm{R} 2=0.045, \mathrm{~F}=2.546, \mathrm{p}=0.020$} \\
\hline
\end{tabular}

\section{Discussion}

It has been detected that most of the students were 19-20 years of age and graduated from Anatolian High School. The graduates of Health Vocational School were quite a small number.

When the educational status of parents of students participated the study were evaluated; it was seen that they especially graduated from elementary school. The number of graduated from university is increased but this number do not exceed $10 \%$. According to The data of 2008 of research of Turkey Demographic and Health Survey; the women were less educated than the men (The Research of Turkish Population and Health, 2008). While 33\% of women have not got any education or completed the elementary school, this percentage was $20 \%$ for men. One in four of women, one in three of men have high school and higher educational status. The educational status of parents and 2008 TNSA data was similar to each other. Although the students graduated from health vocational school was less among the students, Having knowledge about the cancers and the chemotherapy came into mind when it comes to cancer are showed the importance of cancer disease recognized and also it gives a rise to thought 
that there was an effect of mass media on increasing the awareness.

The breast cancer is the most common cancer type for women. The women and young must be knowledgeable about early diagnostic methods and this disease which can cause a great risk for their selves (Ferlay et al., 2015). But it was drawn the attention that in our country there are serious lack of knowledge on these issues among women (Gunel et al., 1995; Karadag, 2010). In the conducted study, it was detected that nearly whole of the students have knowledge about breast cancer and more than half of them have knowledge about Self Breast Examination. It was detected that they obtained the knowledge related to breast cancer and self-breast examination from family/ friend and teacher, communication tools and media, internet and health professionals and scientific resources, respectively. In the study of Golbasi et al. (2010), it was found that the students get the knowledge about SBE from radio/television, friend, Book/Journal, Healthcare personnel, School, family and internet, respectively (Golbasi et al., 2010). In the study of Erkoc et al (2011), it was detected that $15.4 \%$ of first class students have knowledge about SBE and they get this information from $\mathrm{TV}$, internet and journal (50\%), from family and friend $(50 \%)$ and from Friends (50\%) (Erkoc et al., 2011). In the study of Akhtari-Zavare et al. (2015), it was showed that media (magazine and television) were the main sources of information about breast cancer and breast self-examination practice. These findings of other studies (Redhwan et al., 2011; Akhtari-Zavare et al., 2014), suggesting that media is an important source of breast cancer information for women. This is drawn the attention to requirement for training regarding this subject in the educational institution.

There was relatively small portion with a family member who experienced breast cancer. Knowledge of more than half students regarding the breast cancer diagnosis methods allows them to see the disease as a preventable and treatable disease. But in the studies conducted within some cultural groups, it is detected that a fatalistic approach is determinative for screening and treatment of disease. Especially regional and cultural beliefs are effective in shaping attitudes (Guner et al., 2007; Gocgeldi et al., 2008).

According to the responses of students to scale of Health Belief Model used to determine the health belief of them; the average of item point of confidence and barriers sub dimensions were higher. This finding was supported by Yucel et al. (2014) a significant relationship was observed between BSE performance and the perceived barriers and confidence among respondents. Barriers perception expresses the perceived negative aspects in the formation of protective behavior; confidence perception expresses sufficiency in implementing a health behavior (Potter and Perry, 1999; Poss, 2001). In the scope of other health perceptions affecting the attitudes and behaviors of individuals in early diagnosis of breast cancer, there are the benefits of expected health behaviors to individual and barriers perception in implementing the behavior. According to model, it would be expected that a woman who realizes the benefit of behaviors related to early diagnosis of breast cancer and faces less barriers in implementing these behaviors have higher rate for displaying expected health behaviors (Holm et al., 1999; Mikhail and Petro-Nustas, 2001). In displaying the behaviors related to early diagnosis, the benefit perception must be higher than the barriers perception (Champion, 1999). But in the performed study it was determined that the barriers perception was higher. In various studies, it is stated that the main factors blocking the behaviors of women regarding early diagnosis of breast cancer are lack of knowledge, shame, pain, cost, lack of time, fear of receiving radiation, finding the operations unnecessary and concern of encountering a bad result (Yucel et al., 2014; Akhtari-Zavare et al., 2015).

"Confidence perception" used in the study of Champion (1993) was used in the same meaning of description of Bandura as "self-efficacy". In the Gozum and Aksayan studies (2003) this notion, was defined as "self-judgment of individual regarding the capability to do things successfully and to show a significant performance by organizing the required activities". According to Health Belief Model, the women with high health motivation and confidence perception would have high tendency for SBE, mammography, taking clinical breast examination. In the several studies made regarding this subject, the positive effect of health motivation and confidence perception on doing SBE and taking mammography was stated (Mikhail and Petro-Nustas, 2001; Yucel et al., 2014).

Consequently, it was detected that more than half of the students have knowledge about breast cancer and SBE. Even it is determined that the health belief was effected by trust and obstacle perception, knowledge about cancer, the thing came into mind regarding cancer (disease, death etc), knowledge about how is the SBE made and existence of a family member with breast cancer. In the planning of education which would be given to the students, considering these factors would be a guide way. Media must become active in terms of gathering knowledge regarding SBE and breast cancer. The health care professionals must use media more accurate and effectively. The social responsibility projects should be regulated to create awareness regarding cancer is a treatable disease.

\section{References}

Afsharfard A, Mozaffar M, Orang E, Tahmasbpour E (2013). Trends in epidemiology, clinical and histopathological characteristics of breast cancer in Iran: results of a 17 year study. Asian Pac J Cancer Prev, 14, 6905-11.

Akhtari-Zavare M, Hanafiah Juni M, Ismail IZ, Md Said S, A Latiff L (2015). Health beliefs and breast self-examination among undergraduate female students in public universities in klang valley, Malaysia. Asian Pac J Cancer Prev, 16 , 4019-23.

Akhtari-Zavare M, Ghanbari-Baghestan A, Latiffah AL, et al (2014). Knowledge of breast cancer and breast selfexamination practice among Iranian women in Hamadan, Iran. Asian Pac J Cancer Prev, 15, 6531-4.

Aydin I, Gozum S, Karayurt O (2003). The results of the adaptation of champion health belief model scale to Turkish within screening breast cancer, J Res Develop Nurs, 1, 72-5. 
Aydin I, Isikli Z (2004). The belief of midwives and nurses working in preventive health services regarding breast selfexamination, the abstract book of 3. national nursing student congress. University publications, Edirne.

Bjerkaas E, Parajuli R, Weiderpass E, et al (2013). Smoking duration before first childbirth: an emerging risk factor for breast cancer? Results from 302,865 Norwegian women. Cancer Causes Control, 24, 1347-56.

Chad M Barnett, Laura Boehnke Michaud, Francisco J Esteva (2014). Bresat cancer. in 'pharmacotherapy: a pathophysiologic approach', Eds Mc Graw Hill education.

Champion VL (1993). Instrument refinement for breast cancer screening behaviors. Nurs Res, 42, 139-43.

Champion VL (1999). Revised susuceptibility, benefits, and barriers scale for mammography screening. Res Nurs Health, 22, 341-8.

Erbil N, Bolukbas N (2014). Health beliefs and breast selfexamination among female university nursing students in Turkey. Asian Pac J Cancer Prev, 15, 6525-9.

Erkoc A, Oran F, Yorulmaz H (2011). The effects of training on breast self-examination knowledge level of student nurses. Breast Health J, 7, 101-5.

Ersin F, Bahar Z (2013). Barriers and facilitating factors perceived in Turkish women's behaviors towards early cervical cancer detection: a qualitative approach. Asian Pac J Cancer Prev, 14, 4977-82.

Ferlay J, Soerjomataram I, Dikshit R, et al (2015). Cancer incidence and mortality worldwide: Sources, methods and major patterns in GLOBOCAN 2012. Int J Cancer, 136, 359-86.

Fredslund SO, Bonefeld-Jorgensen EC (2012). Breast cancer in the Arctic-changes over the past decades. Int J Circumpolar Health, 71, 1-14.

Gunel N, Oztas D, Uner A, et al (1995). Assessing the behaviors and knowledge of women with 20+ years age. Turkish Oncol $J, \mathbf{1 0}, 60$.

Guner I, Tetik A, Gonener A (2007). Defining the knowledge, attitude and behavior of women regarding breast selfexamination. Gaziantep Med J, 1, 55-60.

Gocgeldi E, Acikel C, Hadse M, et al (2008). Defining attitude and behaviors of a women group in ankara-golbasi regarding breast self-examination. Firat Med J, 4, 261-5.

Golbası Z, Cetin R, Kalkan S, et al (2010). The Knowledge and Behaviors of female university students Related to Breast Self-Examination and Breast Cancer. Breast Health J, 6, 69-73.

Gozum S, Aydin I (2003). The validity of turkish version of champion health belief model scale, the book of 2 . international 9. national congress, antalya.

Gozum S, Aksayan S (2003). Guide II of Intercultural Adaptation of Scale: Psychosometric Features and Intercultural Comparison. J Res Develop Nursi, 5, 3-14.

Giridhara RB, Goleen S, Sharon PC, et al (2011). Breast cancer screening among females in iran and recommendations for improved practice: a review. Asian Pac J Cancer Prev, 12, 1647-55.

Hajian-Tilaki K, Auladi S (2012). Health belief model and practice of breast self-examination and breast cancer screening in Iranian women. Breast cancer, 1-6.

Holm CJ, Deborah IF, Curtin J. (1999). Health beliefs, health locus of control and women's mammography behavior, Cancer Nurs, 22, 149-56.

Jane Lu ZY (1995). Variables associated with breast selfexamination among chinese women.Cancer Nurs, 18, 29-34.

Jirojwong S, MacLennan R (2003). Health beliefs, perceived self-efficacy,and breast self-examination among Thai migrants in Brisbane. J Adv Nurs, 41, 241-9.
Karadag M (2010). Defining the breast self-examination behaviors and beliefs of the students of health school. Turkey Clinics J Nurs Sci, 2, 1-10.

Karayurt O (2003). The adaptation of champion health belief model scale for turkey and the analysis of factors which affect the practicing frequency of breast self-examination, doctoral thesis; Izmir, Ege University.

Kayhan A, Gurdal SO, Ozaydin N, et al (2014). Successful first round results of a Turkish breast cancer screening program with mammography in Bahcesehir, Istanbul. Asian Pac J Cancer Prev, 15, 1693-7

Mikhail BI, Petro-Nustas WI. (2001). Transcultural adaptation of champion's health belief model scales, J Nurs Scholarship, 33, 159-65.

Munro BH, Page EB (1993). Statistical methods for health case research, second edition, j.b. lippincott company, philedelphia.

Poss JE (2001). Developing a new model for cross-cultural research: synthesizing the health belief model and the theory of reasoned action. Adv Nurs Sci, 23, 15.

Potter PA, Perry AG (1999). Basic nursing- a critical thinking approach, fourth edition, St Louis: Mosby Year Book.

Redhwan AA, Dhekra HA, Yuri V BB, et al (2011). Practice and barriers toward breast self-examination among young Malaysian women. Asian Pac J Cancer Prev, 12, 1173-8.

The research of Turkish population and health (2008). http:// www. hips.hacettepe.edu.tr/. Data Accessed: 28 May 2010.

Toriola AT, Colditz GA (2013). Trends in breast cancer incidence and mortality in the United States: implication for prevention. Breast Cancer Res Treat, 138, 665-73.

Troisi R, Altansetseg D, Davaasambuu G, et al (2012). Breast cancer incidence in Mongolia. Cancer Causes Control, 23, 1047-53.

Varughese AA, Poothiode U, Manjula (2015). Descriptive study on selected risk factors and histopathology of breast carcinoma in a tertiary care centre in Kerala, India with special reference to women under 40 years old. Asian Pac $J$ Cancer Prev, 16, 181-4.

WHO (2013). latest world cancer statistics. Retrieved 12 December 2013.

Yasaroglu S (1995). The importance of breast self-examination on early diagnosis of breast cancer and the comparison of breast cancer knowledge level of last class schoolgirls of medical and paramedical department of our university, atatürk university, health sciences institute, nursing department, Master's thesis, Erzurum.

Yilmaz SG, Arslan S (2015). Effects of progressive relaxation exercises on anxiety and comfort of Turkish breast cancer patients receiving chemotherapy. Asian Pac J Cancer Prev, 16, 217-20.

Yilmaz D, Bebis H, Ortabag T (2013). Determining the awareness of and compliance with breast cancer screening among Turkish residential women. Asian Pac J Cancer Prev, 14, 3281-8.

Yucel SC, Orgun F, Tokem Y, Avdal EU, Demir M (2014). Determining the factors that affect breast cancer and self breast examination beliefs of Turkish nurses in academia. Asian Pac J Cancer Prev, 15, 1275-80. 